\title{
Operating Reserve Value at Risk
}

\author{
J. Zhong, Member, IEEE, and F. F. Wu, Fellow, IEEE
}

\begin{abstract}
Operating reserve is traditionally determined as a fixed percentage of the peak load or the largest contingency in a system. In this paper, the probabilistic nature of operating reserve is considered. A risk assessment based approach is proposed to analysis the value of operating reserve. In the proposed approach, the value at risk of a power system is first calculated base on Forced Outage Rates of units. Then, according to the values of system outages, the probability of system loss of value is calculated. Considering operating reserve, the reserve value at risk is obtained by comparing the system loss of values with and without reserve at the same risk level. In the study case, data of IEEE Reliability Test System is used to test the proposed approach.
\end{abstract}

Index Terms - Operating reserve, Value at Risk, risk assessment, system loss of value, system outage.

\section{NOMENCLATURE}

$s: \quad$ total system capacity (MW)

$u$ : $\quad$ system outage (MW)

$v: \quad$ value of outage, $v=v(u)(\$)$

$L: \quad$ system loss of value $(\$)$

$x: \quad$ value variable $(\$)$

$\varepsilon: \quad$ risk level

$l: \quad$ fixed system load (MW)

$R V @ R: \quad$ reserve value at risk

\section{INTRODUCTION}

$\mathrm{I}_{\mathrm{r}}^{\mathrm{N}}$ $\mathrm{N}$ power systems, operation reserves are used for system reliability operation. Backup generation is provided in the event of generator or transmission line failures. Traditionally, operating reserve is set as a fixed percentage of system peak load or equal to the capacity of the largest unit in the system. With the deregulation of power industry and the development of competitive electricity markets, power systems still follow the traditional way of setting operating reserves according to the practice of industry. However, this deterministic method is inconsistent with the economic principles. Since reserve suppliers know the required amount of operating reserves and also know that they would be selected for providing reserve services, they may offer high prices which results in high market price for operating reserves. For example, using a fixed percentage of loads as operating reserve leads to the

This work was supported in part by the HKU Seed Funding Program for Basic Research (project code: 200411159086), in part by the Research Grand Council of Hong Kong under Grant HKU7201/05E.

J. Zhong and F. F. Wu are with the Department of Electrical and Electronic Engineering, The University of Hong Kong, Hong Kong. (e-mail: jzhong@eee.hku.hk and ffwu@eee.hku.hk). high prices in California market.

In power system operation, operating reserve actually act as the role of the insurance against generation capacity due to forced outage. It is one of the means to reduce the operation risk as a result of unexpected failures of generators and transmission lines. Without operating reserves, the consequence will be the loss of load or even system outage in the case of generator or transmission line failures. The economic consequence of system outage should be weighted with the price of purchasing reserve.

With deterministic criteria, operating reserve is determined as a fixed percentage of the peak load or the largest contingency. On the other hands, forced outages and failures of equipment are probabilistic problems. The deterministic measure does not explicitly consider the probability of component failures. When we consider operating reserves, the probabilistic nature of the problem should be taken into account. This leads to risk assessment problem.

In power system planning, probabilistic methodology has been used. As a matter of fact, Loss of Load Probabilistic (LOLP) is used to justify the percentage of load as reserve. The value of loss of load or outage cost has also been applied in power system planning. There is a lot of work about outage costs. A "value of service" (VOS) based generation reliability approach has been developed to combine together utility costs and customer outage costs in setting reserve margins [1]. In [2], a practical value of service based tool is developed to evaluate the reliability of a power system while consider outage costs.

In this paper, we will propose a new approach considering value of outage to balance with the cost of reserve. In the approach, the probability of outage and the acceptable level of risk are considered.

The paper is organized as the following. In section III, a simple example is used to illustrate the basic concept. In section IV, the theory for the operating reserve value at risk is developed. Section V gives a test example. Section VI is conclusions.

\section{BASIC PRINCIPLE}

In this section, we will illustrate the basic principle of the proposed approach by using a simple example.

\section{A. The Value at Risk of a power system}

Assume there are three generators in a simple system. The capacity and the Forced Outage Rate (FOR) of each generator are given in Table I. 
TABLE I

THE CAPACITY AND FORCED OUTAGE RATE OF THREE GENERATORS

\begin{tabular}{|l||c|c|c|}
\hline Generator No. & $\begin{array}{c}\text { Generato } \\
\text { r } 1\end{array}$ & $\begin{array}{c}\text { Generato } \\
\text { r 2 }\end{array}$ & $\begin{array}{c}\text { Generato } \\
\text { r 3 }\end{array}$ \\
\hline Capacity (MW) & 10 & 15 & 20 \\
\hline Forced Outage Rate (FOR) & 0.1 & 0.2 & 0.1 \\
\hline
\end{tabular}

Each generator has two operating states: ON or OUT. The probability of a generator being outage is equal to the forced outage rate given in Table I. For this simple example, the outage rate for generator 1,2 and 3 are 0.1, 0.2, and 0.1, respectively. On the other hand, the probability for each generator to be $\mathrm{ON}$ is $0.9,0.8$ and 0.9 , respectively. Since each generator has two states: ON or OUT, there are eight operating states for the three generators as shown in the first three columns of Table II. The probability of each state is calculated and given in the fifth column of Table II.

TABLE II

THE PROBABILITIES OF GENERATORS ON OR OUTAGE

\begin{tabular}{|c|c|c||c|c|}
\hline $\begin{array}{c}\text { Generator } \\
1\end{array}$ & $\begin{array}{c}\text { Generator } \\
2\end{array}$ & Generator 3 & $\begin{array}{c}\text { Capacity } \\
\text { ON (MW) }\end{array}$ & Probability \\
\hline \hline on & on & on & 45 & 0.648 \\
\hline on & on & outage & 25 & 0.072 \\
\hline on & outage & on & 30 & 0.162 \\
\hline on & outage & outage & 10 & 0.018 \\
\hline outage & on & on & 35 & 0.072 \\
\hline outage & on & outage & 15 & 0.008 \\
\hline outage & outage & on & 20 & 0.018 \\
\hline outage & outage & outage & 0 & 0.002 \\
\hline
\end{tabular}

In Table III, we list the data in the descendent order of total capacities that are ON. The corresponding probability and cumulative probability are given in column 2 and column 3 , respectively. Assume the load of the system is $30 \mathrm{MW}$. For the total available capacities as shown in the Column 1 of Table III, the corresponding system outages (or loss of load) are given in the Column 4 of Table III. In the following, system outage is represented by symbol ' $u$ '.

Suppose the values of outages for the system are given as in Fig. 1, and the numbers on the curve in Fig. 1 are imagined values used to illustrate the principal of proposed approach. From the curve, we can find the corresponding values of system outages, as shown in the $5^{\text {th }}$ column of Table III.

TABLE III

The Probabilities of System OUtAgES AND VALUE OF OUTAGE

\begin{tabular}{|c||c|c|c|c|}
\hline $\begin{array}{c}\text { Capacity } \\
\text { ON (MW) }\end{array}$ & Probability & $\begin{array}{c}\text { Cumulative } \\
\text { probability }\end{array}$ & $\begin{array}{c}\text { System } \\
\text { outage } \\
(\mathrm{MW})\end{array}$ & $\begin{array}{c}\text { The value } \\
\text { of outage } \\
(\$)\end{array}$ \\
\hline \hline 45 & 0.648 & 1 & 0 & 0 \\
\hline 35 & 0.072 & 0.352 & 0 & 0 \\
\hline 30 & 0.162 & 0.280 & 0 & 0 \\
\hline 25 & 0.072 & 0.118 & 5 & 100 \\
\hline 20 & 0.018 & 0.046 & 10 & 150 \\
\hline 15 & 0.008 & 0.028 & 15 & 230 \\
\hline 10 & 0.018 & 0.020 & 20 & 350 \\
\hline 0 & 0.002 & 0.002 & 30 & 800 \\
\hline
\end{tabular}

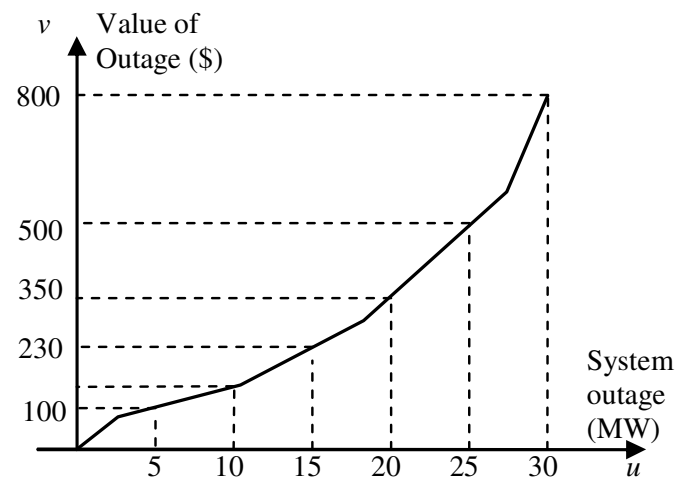

Fig. 1. The value of outages

From the Column 3, 4 and 5 of Table III, we can find the following: The probability of the system having an outage bigger than 5MW is 0.118 , and the corresponding loss value is $\$ 100$. The probability of outage greater than 10MW (or $\$ 150$ ) is 0.046 , and so on. We can get the curves for probability of system outage as shown in Fig. 2.

If we fix a risk level, say, 0.02 , the value at risk of this risk level is $\$ 350$, which can be found in the $8^{\text {th }}$ row of Table III.

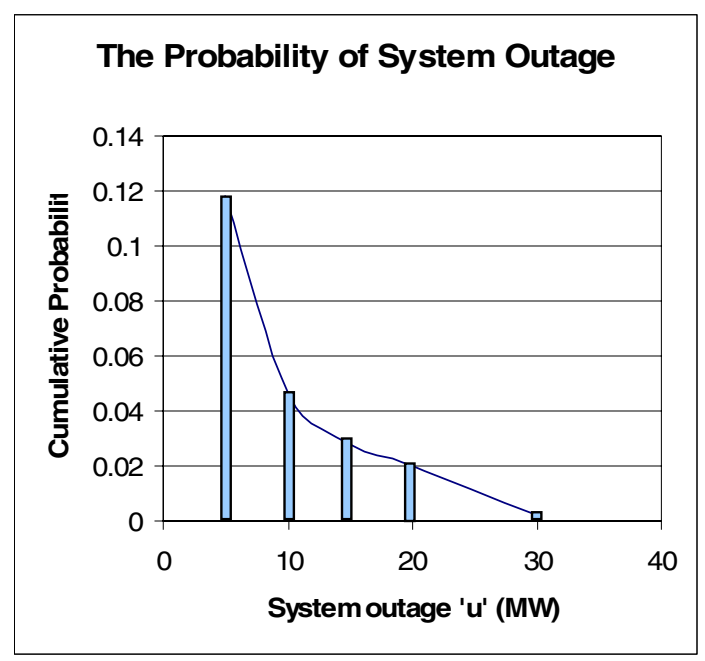

Fig. 2 The probability of system outage

\section{B. The Value at Risk of a power system with reserve}

In Sub-section III.A, we have obtained the value at risk of a simple power system. In this sub-section, we will consider the situation of a power system with reserve.

Assume a reserve of $10 \mathrm{MW}$ is added to the system. It is assumed to be a deterministic reserve and always available. The $4^{\text {th }}$ and $5^{\text {th }}$ column of Table III can be re-calculated, and the results are given in Table IV.

From Table IV, we can find the new value at risk after adding a reserve to the system. For the same risk level, 0.02, the value at risk is $\$ 150$ for the system with reserve. The loss of value at the risk level 0.02 has decreased from $\$ 350$ to $\$ 150$ if the system has an operating reserve of $10 \mathrm{MW}$. So, the reserve value at risk is $\$ 350-\$ 150=\$ 200$ at the risk level of 0.02 . That means the reserve value is $\$ 200$ for customers. Customers would like to be outage if they have to pay for more than $\$ 200$ to buy reserves. 
TABLE IV

THE Probabilities of System OUTAGES AND THE VALUES OF OUTAGES

\begin{tabular}{|c|c|c|c|}
\hline $\begin{array}{c}\text { Capacity } \\
\text { ON (MW) }\end{array}$ & $\begin{array}{c}\text { Cumulative } \\
\text { probability }\end{array}$ & $\begin{array}{c}\text { System } \\
\text { outage } \\
(\mathrm{MW})\end{array}$ & $\begin{array}{c}\text { The value } \\
\text { of outage } \\
(\$)\end{array}$ \\
\hline \hline 45 & 1 & 0 & 0 \\
\hline 35 & 0.352 & 0 & 0 \\
\hline 30 & 0.280 & 0 & 0 \\
\hline 25 & 0.118 & 0 & 0 \\
\hline 20 & 0.046 & 0 & 0 \\
\hline 15 & 0.028 & 5 & 100 \\
\hline 10 & 0.020 & 10 & 150 \\
\hline 0 & 0.002 & 20 & 350 \\
\hline
\end{tabular}

In the next section, we will illustrate the theory of the approach.

\section{THEORY}

\section{A. The probability of system loss of value}

Assume the system load is fixed as a value $l$. The system capacity, which is the sum of individual generation capacities, is represented by symbol $s$. The loss of load (or system outage) is represented by symbol $u$. We can define the system outage $u$ as following:

$$
u=\left\{\begin{array}{cc}
l-s & \text { if }(l-s) \geq 0 \\
0 & \text { if }(l-s)<0
\end{array}\right.
$$

The symbol $v$ is used to represent the cost associated with system outage, which is also called as outage cost or value of loss of load. The cost is a function of system outage, and can be expressed as

$$
v=v(u)
$$

Suppose we can find the function of $v(u)$ by using the concept of Value of service. The function is a monotonically increasing function. Fig. 1 is an illustrative curve of the relationship between $v$ and $u$.

If we take into account the forced outage, the individual generation capacity is a random variable. So, the system capacity $s$, which is the sum of individual generation, is a random variable. System outage $u$ is a function of system capacity $s$, as in (1), so $u$ is a random variable. Outage cost $v$ is also a random number, since it is a function of $u$, as shown in (2).

Now, we want to obtain the probability distribution for the system loss of value " $L$ " that is greater than and equal to a given value $x$. To explain how to obtain the probability, we use the example discussed in Section III. Say, if we want to calculate the probability for system loss of value greater and equal to $\$ 350$, we find in Table III that the corresponding system outage is 20MW. So, the probability for system loss greater and equal to $\$ 350$ is equal to the probability of system outage greater and equal to $20 \mathrm{MW}$, which is 0.02 . So, the probability distribution for the system loss " $L$ " greater than and equal to a given value $x$ can be obtained by using (3).

$$
\operatorname{Pr}\{L \geq x\}=\left\{\sum_{u \geq K} p(u) \mid v(K)=x\right\}
$$

Where, $x$ is a given value of system loss, $K$ is the outage capacity corresponding to loss value $x . \mathrm{v}$ is the value of outage. $p(u)$ is the probability of outage capacity equal to $u$.

As we have discussed above, if $x$ is set as $x=\$ 350$, the corresponding $K$ can be found to be $K=20 \mathrm{MW}$ in Table III and Fig. 1. From Table III and Fig. 2, the probability for $\mathrm{u} \geq 20 \mathrm{MW}$ is found to be $\sum_{u \geq 20} p(u)=0.02$.

We can describe the process of finding system loss of value in Fig. 3. The lower-left curve is the cumulative probability for outage capacity, $P(u) \sim u$. The lower-right curve is the value of outage, $v \sim u$. In Section III, we have illustrated these two curves in Fig. 2 and Fig. 1, respectively. Now we are seeking for the probability distribution of system loss bigger than value $x$, i.e. $P(x)=\operatorname{Prob}\{L \geq x\}$. For a given value $\mathrm{X}$, we first try to find how much system outage worth value $\mathrm{X}$ on the value of outage curve $(v \sim u)$. Assume outage capacity "U" is found that worth value " $\mathrm{X}$ ". Then we try to find the probability of outage capacity greater and equal to $U$. The found probability $\mathrm{P}(\mathrm{U})$ is the probability of system loss greater and equal to value $X$. In the end, the probability distribution of system loss greater and equal to value $x$ is found as the upper curve in Fig. 3.

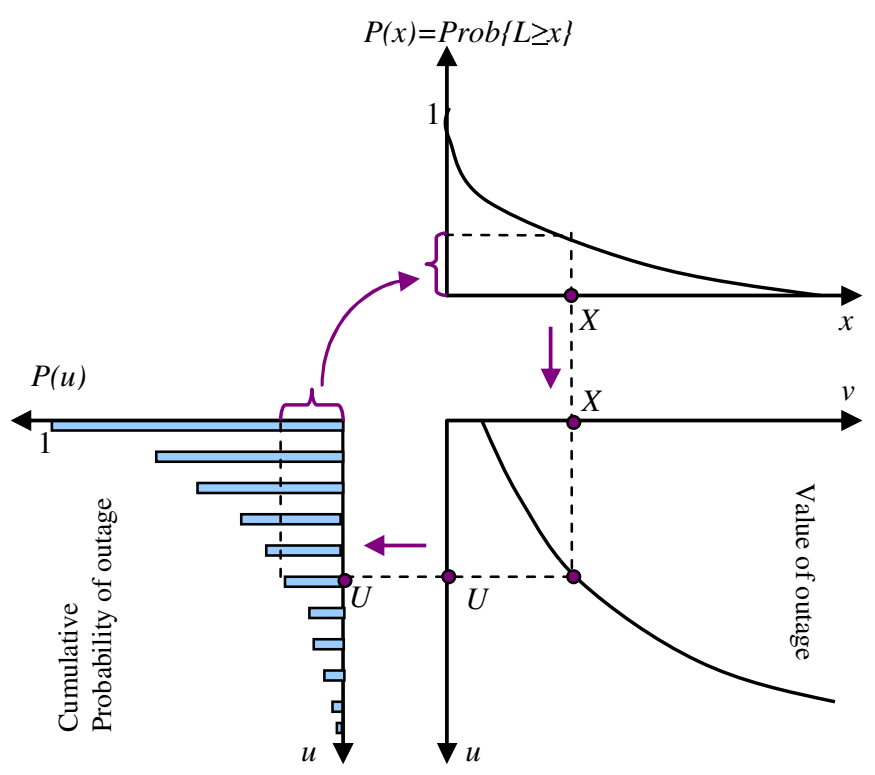

Fig. 3. The probability of system loss of value

\section{B. The probability of system loss of value considering operating reserve}

Consider there is a deterministic operating reserve added to the system. The reserve is represented using symbol $r$. The system capacity and outage capacity after adding reserve are represented using symbol $s^{\prime}$ and $u$ '. So, we have the following,

$$
s^{\prime}=s+r
$$




$$
u^{\prime}=\left\{\begin{array}{cl}
l-s^{\prime} & \text { if }\left(l-s^{\prime}\right) \geq 0 \\
0 & \text { if }\left(l-s^{\prime}\right)<0
\end{array}\right.
$$

Replace s' with (4) and (1), we can obtain,

$$
u^{\prime}=\left\{\begin{array}{cc}
u-r & \text { if }(u-r) \geq 0 \\
0 & \text { if }(u-r)<0
\end{array}\right.
$$

Considering a system reserve ' $r$ ', the outage capacity corresponding to value $X$ is $U^{\prime}=U-r$, which is a shift of the outage without reserve, as shown in Fig. 4. A new probability of outage U' can be found, and it equal to the probability of system loss greater and equal to $X$ with operating reserve ' $r$ '. A new probability distribution curve can be found for the system with reserve as shown in Fig. 4. Compare to the probability curve without reserve, we can see that the probability of system loss greater than a given value $\mathrm{X}$ decreased if system has operating reserve. The probability curve of loss of value shift to left after adding reserve to the system.

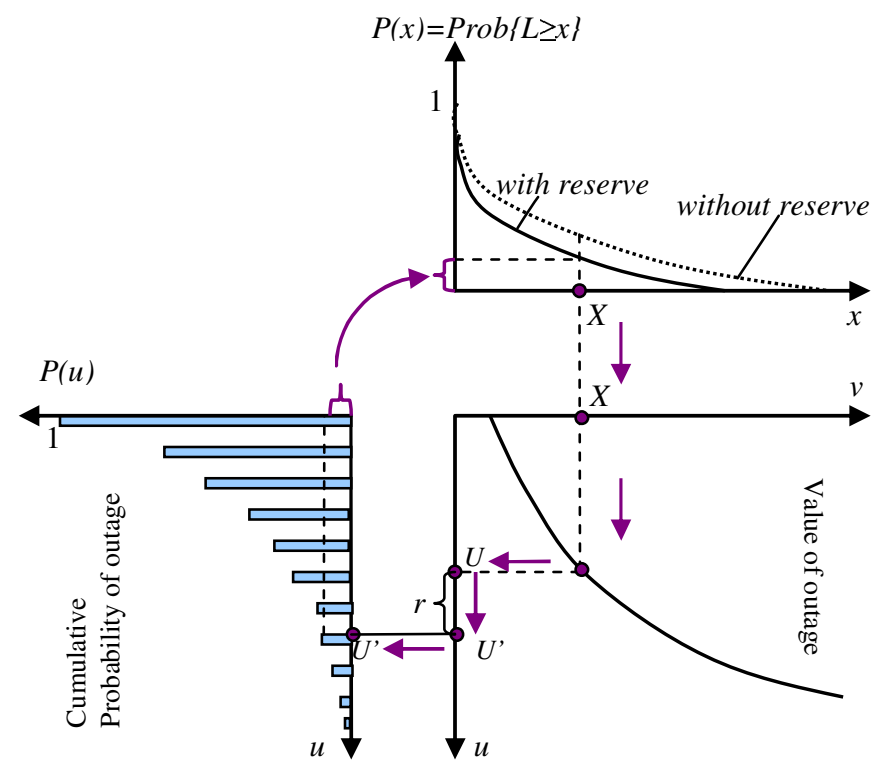

Fig. 4. The probability of system loss of value with operating reserve ' $r$ '.

To further discuss the problem, we draw the upper curve of Fig. 4 individually in Fig. 5. For a given probability, or risk level, the corresponding value for the system without reserve is $x$, and for the system with reserve, the value is $x^{\prime}$. The difference between $x$ and $x^{\prime},\left(x-x^{\prime}\right)$, is regarded as the reserve value at the given risk level, $R V @ R$.

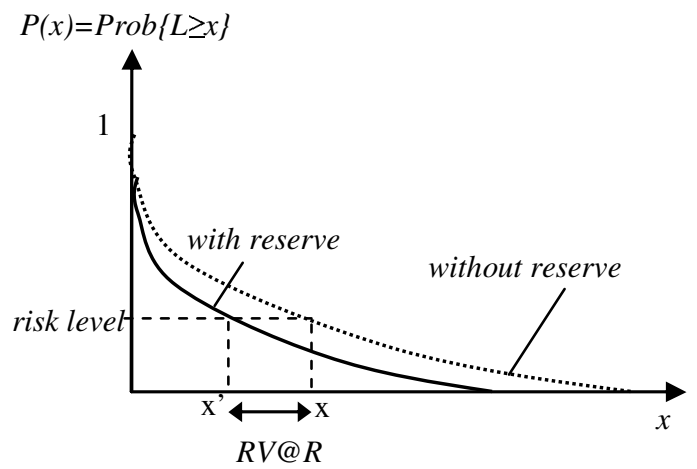

Fig. 5. The probability of system loss of value with and without reserve.

Assume a given risk level is $\varepsilon$. For the system without reserve, the probability for loss value $x$ is:

$$
P(x)=\sum_{u \geq v^{-1}(x)} p(u)=\varepsilon
$$

Where, $\varepsilon$ is the risk level.

For the system with reserve ' $r$ ', the probability for loss value $x$ is:

$$
P\left(x^{\prime}\right)=\sum_{u^{\prime} \geq v^{-1}\left(x^{\prime}\right)} p\left(u^{\prime}\right)=\mathcal{E}
$$

According to (6), $u^{\prime}=u-r$, we can obtain the relationship between $x^{\prime}$ and $x$, as following,

$$
\begin{aligned}
& v^{-1}\left(x^{\prime}\right)=v^{-1}(x)-r \\
& \text { so, } r=v^{-1}(x)-v^{-1}\left(x^{\prime}\right)
\end{aligned}
$$

Then, a curve can be drawn to represent (9) as shown in Fig. 6.

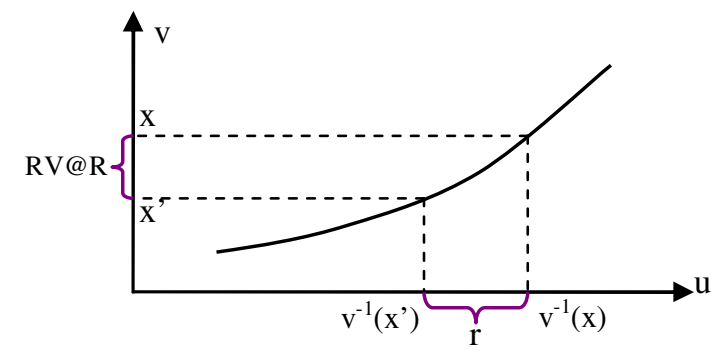

Fig. 6. reserve value at a risk level

By approximation, for a given value $\mathrm{X}$, we can find the reserve value at risk as following:

$$
\begin{aligned}
& R V @ R=r \times\left(\frac{d v(u)}{d u} \mid v=X\right) \\
& \text { so, } \quad \frac{R V @ R}{r}=\frac{d v(u)}{d u} \mid v=X
\end{aligned}
$$

From Fig. 6 and (11), we can conclude by approximation that, if the system loss of value is required to be less than $\mathrm{X}$, the reserve value at risk is the slope of the value of outage curve at point $X$.

\section{EXAMPLE}

In this section, we will test the proposed approach using the generator data given in IEEE reliability test system [3]. 
There are nine generators in the system. Their capacity and Forced Outage Rate (FOR) are given in Table V. The total capacity of the system is $1360 \mathrm{MW}$, and the total load is 950MW.

TABLE V

CAPACITY AND FOR OF GENERATORS

\begin{tabular}{|c|c|c|}
\hline Unit No. & $\begin{array}{c}\text { Unit Size } \\
\text { (MW) }\end{array}$ & $\begin{array}{c}\text { Forced Outage } \\
\text { Rate }\end{array}$ \\
\hline 1 & 12 & 0.02 \\
\hline 2 & 20 & 0.10 \\
\hline 3 & 50 & 0.01 \\
\hline 4 & 76 & 0.02 \\
\hline 5 & 100 & 0.04 \\
\hline 6 & 155 & 0.04 \\
\hline 7 & 197 & 0.05 \\
\hline 8 & 350 & 0.08 \\
\hline 9 & 400 & 0.12 \\
\hline
\end{tabular}

Assume the reserve is $100 \mathrm{MW}$, the probability of outage is calculated for the system with reserve and without reserve, respectively, as shown in Fig. 7. We can see that, the probability of a system outage is smaller in the system with reserve compare to the system without reserve.

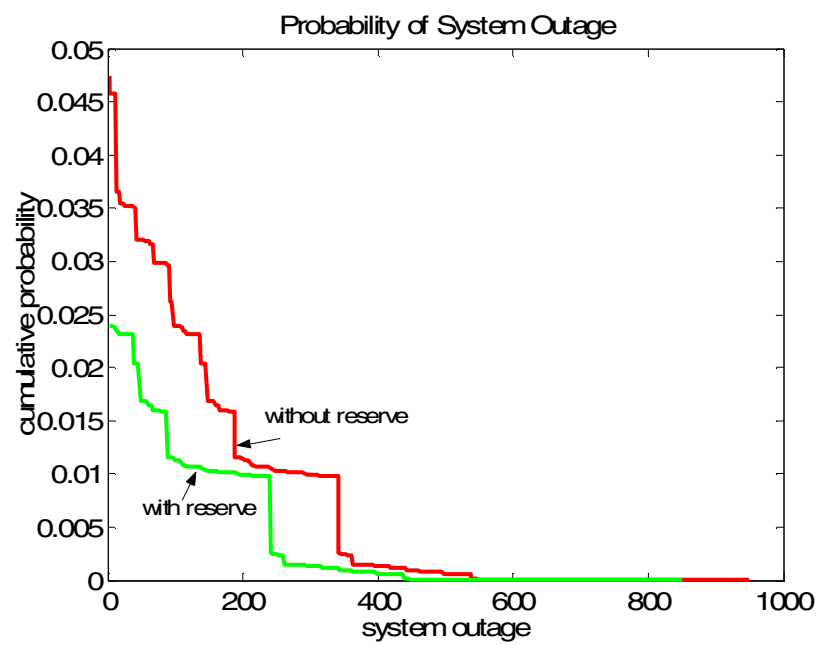

Fig. 7. Probability of System Outage

Assume the value of system outage is a function as (12). The curve is shown as in Fig. 8.

$v=a u^{2}+b u+c$

Where, $v$ is the value of outage and $u$ is system outage.

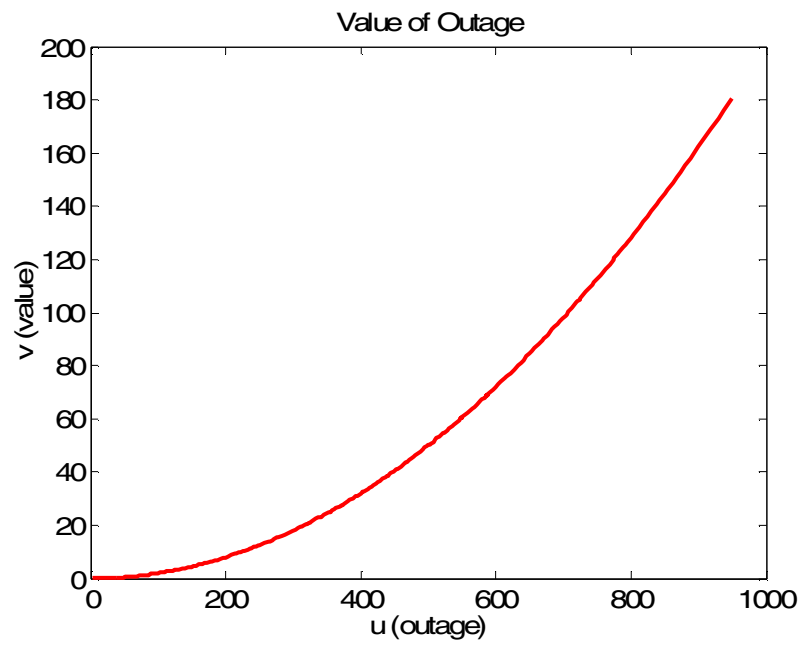

Fig. 8. The Value of Outages

Using the proposed approach, for different given value $\mathrm{x}$, we can find the corresponding probability of the system loss of value $\mathrm{x}$, as shown in Fig. 9. It can be found from the figure that, the probability of loss value bigger than 60 is zero. After considering system reserve, the probability of loss value bigger than 40 is zero.

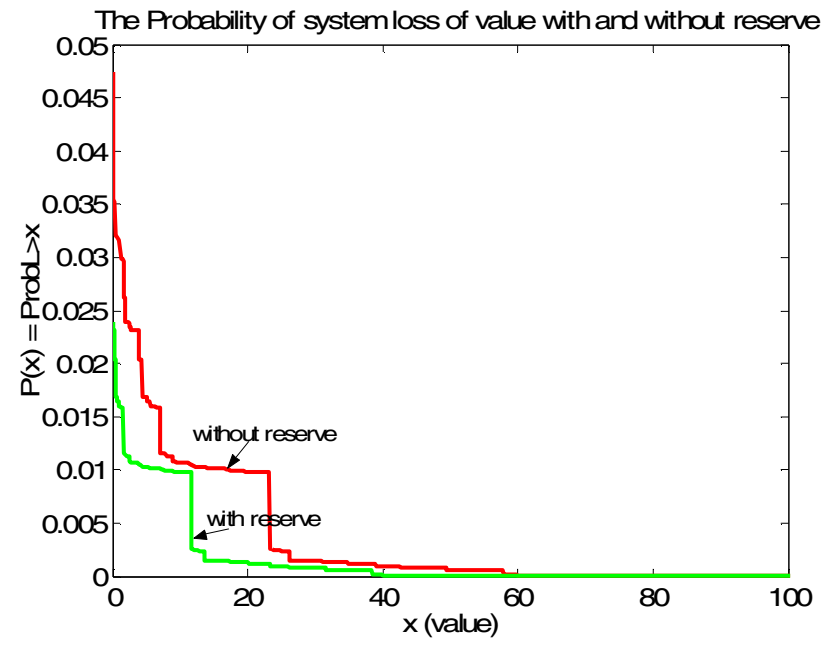

Fig. 9. The Probability of System Loss of Value with and without Reserves

According to Fig. 5, for a given risk level, the difference between the two loss values of systems with and without reserve is the reserve value at the given risk level. Fig. 10 shows the reserve values at different risk levels. From the figure, we can see that at the risk level 0.005 , the value of reserve is 11.6. In other words, for a guaranteed outage probability that is not more than $0.5 \%$, the value of reserve is 11.6, and the customers would like to be outage if they have to pay for more than 11.6 to buy reserves. 


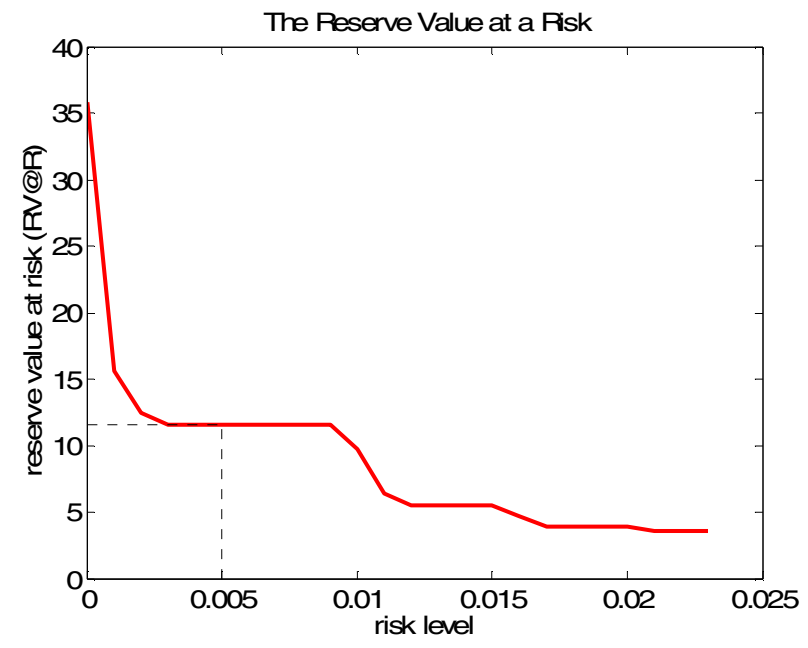

Fig. 10. The Reserve Values at Different Risk Level

On the other hand, we calculated the reserve value at risk level 0.005 by using equations (10) and (11) that we have derived in Section IV. The reserve value is calculated to be 11.66 at the risk level 0.005 by using (10). It is proved that the same reserve value at risk can be obtained by using the approach proposed in Fig.3. - Fig.5, and the derived equations (10) and (11). The reserve value at risk is the slope of the value of outage curve at value $\mathrm{X}$.

\section{CONCLUSIONS}

In this paper, a method is proposed to calculate the reserve values at given risk levels. The value of operating reserves can be obtained for a guaranteed risk level. Customers would not pay for more than the obtained reserve value for a given outage risk level. It is shown that the value of reserves decreases with the increase of risk level. It is also proved that the reserve value at risk is the slope of the value of outage curve at the point of value " $X$ ".

\section{REFERENCES}

[1] A. F. Vojdani, F. D. Williams, W. Gambel, et al "Experience with Application of Reliability and Value of Service Analysis in System Planning," IEEE Trans.on Power Systems, vol. 11, No. 3, August. 1996, pp. 1489-1496.

[2] S. Burns and G. Gross, "Value of Service Reliability", IEEE Trans. On Power Systems, Vol. 5, No. 3, August, 1990, pp. 825-833.

[3] "The IEEE Reliability Test System - 1996, A report prepared by the Reliability Test System Task Force of the Application of Probability Methods Subcommittee”, IEEE Trans. on Power Systems, Vol. 14. No. 3, August 1999, pp. 1010-1020.

\section{BIOGRAPHIES}

Jin Zhong (S'00, M'05) received the B. Sc. (Eng.) degree from Tsinghua University, Beijing, China, in 1995 and the M. Sc. (Eng.) degree from the Electric Power Research Institute, Beijing, in 1998, and the Ph.D degree from Chalmers University of Technology, Gothenburg, Sweden, in 2003.

She is an Assistant Professor in the Department of Electrical and Electronic Engineering at the University of Hong Kong. Her areas of interests are electricity sector deregulation, ancillary service pricing and transmission planning.

Felix F. Wu (Fellow, IEEE) is the Philip Wong Wilson Wong Professor in Electrical Engineering at the University of Hong Kong, where he served as Pro Vice Chancellor (Vice President) from 1997 to 2001. He is also a ProfessorEmeritus at the University of California, Berkeley, where he has been on the Faculty since 1974. 